\title{
Deflationary Truth and the Problem of Relativistic Grounds of Emotivism
}

\author{
Mikhail G. Khort, Artur R. Karimov, Alexei S. Guryanov
}

\begin{abstract}
The article discusses the Frege-Geach problem, which is considered one of the most serious difficulties for emotive meta-ethics. The paper describes how recognition of an emotive content by moral statements in the form of attitudes leads to the emergence of the Frege-Geach problem. The essence of the problem is explained, which consists in the impossibility to make a logical conclusion in a situation of mixed contexts, when the antecedent has a value meaning, and the consequent is descriptive. The authors consider one way to solve this problem, which involves the use of a deflationary theory of truth. It is proved that the adoption of deflationism about the truth makes it possible to draw a logical conclusion in mixed contexts. They also raise the question of whether the application of deflationary truth concept is sufficient to avoid the relativistic effects of emotivism on normative ethics. The authors note that the synthesis of deflationism and emotivism is not able to explain the internalism of moral statements, which always have a hidden prescriptive modality. The conclusion is made that deflationism does not allow emotivism to avoid relativistic consequences in the field of normative ethics. Therefore, the authors conclude that emotivism should be called the nihilistic theory of the rationale for moral statements.
\end{abstract}

Keywords: Metaethics, Relativism, Emotivism, Attitude, Deflationary truth, The Frege-Geach problem.

\section{INTRODUCTION}

Emotivism has always occupied a special place among all metaethical theories: the concept according to which the criterion of validity for moral statements is not applicable.

Emotivists argue [1] that moral statements do not express beliefs. They are the expression of a certain emotion of a speaker, as a rule, the emotion of some fact approval or disapproval. Moral sentences do not describe the world, do not perform the descriptive function of the language, they are rather an expression of a speaker's attitude. Attitude is a subjective assessment of a fact, something that is beyond the scope of its simple statement. Attitude is the projection into the world of feelings and experiences of a subject (therefore, some varieties of emotivism are also called projectivism or expressivism). For example, a person may be horrified by the sight of a huge spider. The spider itself is a fact. The emotion of horror that a person experiences in relation to a spider is not included in the structure of this fact; it is an attitude to perceive a fact in a certain way, that is, a projection of this fact.

For emotivism, a moral sentence is not a statement about emotions, but the very expression of emotion. Therefore, any

Revised Manuscript Received on November 08, 2019.

* Correspondence Author

Mikhail G. Khort, Kazan Federal University

Artur R. Karimov, Kazan Federal University

Alexei S. Guryanov, Kazan State Power-Engineering University, Kazan State Medical University, Russia sentence in which there is a moral term is always singular. And therefore, starting from the verification theory of meaning, emotivists come to the conclusion that sentence-sets that are not found in intersubjective experience cannot be true or false: "If I now <...> say, "Stealing money is wrong" I produce a sentence which has no factual meaning - that is, expresses no proposition that can be either true or false" [2].

The main accusation faced by emotivism as a metaethical theory is the indication of its relativistic conclusions regarding normative ethics [3], [4]. This accusation is expressed, inter alia, through the Frege-Geach problem, which indicates the inconsistency of emotivist non-cognitivism with linguistic intuition and the logical law of identity.

\section{METHODS}

We use the conceptual analysis method. This method involves the term conceptual core identification by comparing different contexts of its use.

\section{RESULTS AND DISCUSSION}

The Frege-Geach problem arises during consideration of moral utterances as the constituent elements of a logical conclusion, that is, in the context of a complex utterance, where the logical connective of the implication "if ... then ..." connects a simple utterance with a moral term and a simple utterance without moral terms.

The wording of this accusation belongs to the logician $\mathrm{P}$. Geach, who, in turn, derived his argument from the semantic ideas of G. Frege regarding the essence of statements and the conclusion on modus ponens. V.V. Ogleznev writes the following: "Trying to prove that the meaning of sentences is their true value, Frege came to the conclusion that the issue of truth arises only when we move from a simple statement of thought to its affirmation. Therefore, from his point of view, it is necessary to distinguish the following in the structure of the affirmative sentence: 1) grasp of thought - thinking; 2) recognition of thought truth - judgment; 3 ) demonstration of this judgement - the statement $\langle\ldots\rangle$ perhaps this is the thesis about three-level structure of the affirmative sentence that Geach calls "Frege point", from which he derives his own argument against cognitivism: “... The idea has the same content, regardless of whether we accept its truth or not; a judgment can be found in discourse both as a statement and in a different capacity, but at the same time remain the same judgment" [5].

Let us consider two conclusions: I, which does not have composite moral statements and conclusion II, which has those. 
(1) If it rains outside, the asphalt is wet.

(2) It is raining outside.

(3) Therefore, the asphalt is wet.

II:

(1) If it is wrong to beat people, then $\mathrm{X}$ does not beat people.

(2`) Beating people is bad.

(3`) Therefore, $\mathrm{X}$ does not beat people.

What is the difference between the case (I) and (II)? If we formalized these statements, we saw that their form seems to be the same. Accordingly, there is no logical contradiction to make a conclusion (II). The problem arises if we take a non-cognitive (so far emotivist) position on the semantics of moral terms, that is, we accept that these are the attitudes. Then it turns out that an intuitively clear and permissible implication (1') is impossible, and the statement (2') differs significantly from (2). The antecedent (2) in (I) has the same meaning both as an integral part of the implication, and as a single simple proposition (i.e., without introduction). In both cases, the statement "it rains outside" means exactly what it means - a certain state of affairs, true, in the case of the actual presence of the indicated state of affairs. But in (II), during adoption of non-cognitive semantics, the antecedent in (1') and the utterance (2`) are different utterances. In other words, the conclusion ( $3^{`}$ ) is intuitively obvious, but logically impossible, because otherwise one would either have to violate the law of identity or accept that a statement like "stealing is bad" has a descriptive meaning. The Frege-Geach problem arises when we consider the implication and logical conclusion assuming the non-cognitive thesis that moral statements are not statements, but attitudes. The following question arises: is the general complex sentence an attitude or not? For emotivists, it is not, because it contradicts the very thesis about the attitude as a single sentence with emotive content. On the other hand, such a statement is quite formalizable and intuitive.

L.D. Lamberov illustrates the Frege-Geach problem by examples with a mixture of moral and descriptive contexts, not only in the case of the conclusion on modus ponens: "Let's look at another example: "Lies is bad, or they lied to me at school". How should this statement be understood, where are its components? Is "or" a connective element? Suppose the statement "Lies is bad" is understood non-cognitively. Suppose this statement is interpreted as an expression of rejection of lie or negative emotion about lie. Obviously, a complex statement can also be made by such a subject who does not experience negative emotions about lies and accepts lies (due to ignorance of some facts). You can slightly modify the example in question, so that the problem becomes even more obvious, as follows: "Either you did wrong by lying to me, or they lied to me at school." What is the significance of this statement, subject to the adoption of non-cognitive analysis? It does not boil down to the fact that either someone lied to the speaker or the speaker was lied at school" [6].

Thus, the problem of Frege-Geach is in the fact that within the framework of non-cognitive semantics it is impossible to make a meaningful logical conclusion. And this, in turn, means that moral discourse is meaningless and unreasonable. It follows that ethics built on emotivistic foundations will be relativistic.

It is possible to solve the Frege-Geach problem by creating an anti-metaphysical concept of truth that would not connect the truth of sentences with metaphysical entities. In essence, this concept should state that truth is not a predicate. A similar concept is deflationism.

According to Y. V. Shramko, the general scheme for any classical inflationary concept of truth development is the following: " $\mathrm{x}$ is true if and only if $\mathrm{x}$ has the property $\mathrm{F}$ ", where $\mathrm{F}$ is some (new) fundamental attribute designed to express the essence of truth" [7]. Unlike inflationism, deflationary concepts of truth are not based on the world, but on language. They seek to show that truth is not some entity or property, but a special logical sign. Therefore, the definition of the deflationary theory of truth will be as follows: " $<\ldots>$ this is the theory of truth, according to which the concept of truth is understood as a metaphysically empty concept that performs specific logical-linguistic functions in the language (generalization, indirect speech, "semantic" ascension) and is fully explainable using the equivalence scheme. One can distinguish the general form of the deflationary equivalence scheme: (DT) $<$ p $>$ true $\equiv p$, where " $<p>$ " means the name of the statement "p" "[8].

Thus, the difference between inflationism and deflationism about truth is that deflationism does not require pointing out the conditions for the truth of sentences, while for inflationary concepts, the conditions of truth are the very meaning of sentences. For example, neopositivist verification as a condition of truth is the meaning of a sentence. Classical emotivists (Ayer, Stevenson), being positivists and adopting a verification theory of meaning, therefore, were initially within the framework of one of the inflationary theories of truth. Therefore, the Frege-Geach problem was unsolvable for them. Because of this problem, they and their followers had to start developing the deflationary theory of truth [9]. They could solve it, but then they would have to stop being positivists in the classical sense. They should have accepted that meaning is not the relationship between the World and the language, but an intralinguistic practice. L. D. Lamberov writes that "from deflationism regarding truth it follows that meanings should be understood as naturalistic properties reducible to use. Thus, deflationary theories of truth are the rationale for the theory of meaning as use" [6]. Here we can recall the Wittgenstein concept of meaning as use. L. Wittgenstein is not a theorist of deflationism, but, as we see, his theory is prolegomena of both deflationism and non-cognitivism. Moreover, unknowable facts are "deflationary" facts, from the semantic point of view (the facts that could take place). This concept is introduced by the British Paul Horwich in order to explain the mechanism for truth determination in deflationary contexts. It consists in the fact that "substitutions into a scheme (DT) can be considered as particular definitions of the concept of truth for specific statements whose substitution is carried out" [10]. This is a logical solution to the Frege-Geach problem: having adopted deflationism, we must conclude that not only the prescriptions, but also any statements in the limit do not represent anything, and their truthfulness is an internal property of the sentences themselves, connected with the fact that they acquire significance only in use. This means that moral sentences can be deflationary true, and they must be interpreted "as the statements expressing the speaker's personal attitude (for example, from the point of view of expressivist non-cognitivism), [and then it should be accepted that] the statement is recognized as true in the "playable" 
language game even if there are no real facts about morality and moral values" $[10,11,12]$.

Does emotivism avoid accusations of skepticism using the deflationary theory of truth to solve the Frege-Geach problem? Here we are faced with the problem of transition from the metaethical level of analysis to argumentation in the field of normative ethics. Deflationism eliminates truth as a real property, endowing it with a purely syntactic role. But with the help of deflationism it is impossible to solve the problem of internalism of moral utterances, which always have a hidden prescriptive modality. The Frege-Geach problem, therefore, has several aspects. The first of them is purely logical, connected with the conclusion making in mixed contexts. It is solved using the deflationary theory of truth. But because of this, the second aspect of the problem arises, which is related to the fact that the formalization of moral statements (with a prescriptive nature) using the deflationary theory of truth is not consistent with the acceptance of the emotive thesis that the content of moral statements is an arbitrary attitude $[13,14]$.

The internalism of moral statements implies the realism of values, and people act as if it goes without saying, even if they agree with the theses of emotivism. Thus, the position of the emotivist is in any case the position of a skeptic and relativist, even if he accepted the deflationary theory of truth.

\section{CONCLUSIONS}

Thus, it can be argued that:

a) The Frege-Geach problem concerns not only the semantic foundations of emotivism, but also the question of the internalism of moral utterances.

b) The solution of the Frege-Geach problem through an appeal to the deflationary theory of truth leads to a new difficulty - the problem of internalism of moral statements.

c) Since emotivism, as a metaethical approach, could not develop an adequate theory of moral statement substantiation, we can state the failure of normative ethical systems based on its foundation.

\section{SUMMARY}

Summing up, we can say that from the point of view of argumentation, there is no need to "save" ethics, endowing moral statements with psychological significance. Emotivists, trying to avoid relativism, violate the sequence of their own argumentation. For example, Ayer, who is the most consistent in expression of the emotive approach essence to ethics, was also a well-known anti-metaphysician. In his book, he convincingly shows the meaninglessness of both metaphysical and ethical statements using the same arguments. At the same time, he "eliminates" the first ones, recognizing the need, although meaningless, of the second. But in order to avoid moral nihilism, Ayer must indicate a criterion for the significance of moral statements, which he did not do. Other emotivists also did not find such criteria, which may indicate the failure of the emotivist project in metaethics.

\section{ACKNOWLEDGEMENTS}

The work is performed according to the Russian Government Program of Competitive Growth of Kazan Federal University.

\section{REFERENCES}

1. S. Satris, "Ethical Emotivism", Springer, pp. 26-51, 1987.

2. A. Ayer, "Language, Truth and logic", Dover Publications, p. 107, 1946.

3. J. Lemos, "The Problems with Emotivism”, Journal of Philosophical Research, № 25, pp. 285-309, 2000

4. J. Lyou, "A Critical Study on A. J. Ayer's Emotivism”, Journal of Ethics, № 1 (111), pp. 1-30, 2016.

5. V. Ogleznev. "The Frege-Geach problem and ascriptive statements", Philosophy of Science, No. 1 (60), p. 41, 2014.

6. L. Lamberov, "Noncognitivism in ethics and deflationism: the problem of general methodological foundations", Scientific Bulletin of the Omsk Academy of the Ministry of Internal Affairs of Russia, No. 3 (50), p. 36, 2013.

7. Ya. Shramko. "The predicate of truth in counterfactual contexts: for defense of deflationism". Epistemology \& Philosophy of Science, No. 2, p. 81,2011

8. L. Lamberov. "Deflationism as a metaphysical concept". Bulletin of Tomsk state university. Philosophy. Sociology. Political Science, No. 4 (24), p. 34, 2013.

9. K. Swan, "Emotivism and deflationary truth", Pacific Philosophical Quarterly, № 83(3), p. 276, 2002.

10. L. Lamberov. "The Frege-Geach problem: (I) on the possibility of solution in the deflationary vein," Vestnik NSU. Series: Philosophy, Vol. 11. Vol. 3, p. 9, 2013.

11. Pakdel, M., \& Talebbeydokhti, A. The Effect of Adjustment Announcement of Predicted Profit on Price and Trading Volume of Listed Companies in Tehran Stock Exchange. Dutch Journal of $\begin{array}{llll}\text { Finance and } & \text { Management, }\end{array}$ https://doi.org/10.29333/djfm/5825(2018).

12. Melo, R., Bezerra, M. C., Dantas, J., Matos, R., de Melo Filho, I. J., Oliveira, A. S., ... \& Maciel, P. R. M. Sensitivity analysis techniques applied in cloud computing environments. In 2017 12th Iberian Conference on Information Systems and Technologies (CISTI) (pp. 1-7). IEEE. (2017, June).

13. Tejeda, S., \& Dominguez, A. Influence of Interactions in the Collaborative Solving of a Velocity Problem. International Electronic Journal of Mathematics Education, 14(1), 91-108. (2019).https://doi.org/10.12973/iejme/3979

14. Shayakhmetova, D., \& Chaklikova, A. Development of the intermediator of intercultural communication based on public argumentative speech. Opción, 34(85-2), 149-185. (2018). 